\title{
Bridging the Divide between Genomic Science and Indigenous Peoples
}

\author{
Bette Jacobs, Jason Roffenbender, JeffCollmann, Kate Cherry, \\ LeManuel Lee Bitsói, Kim Bassett, and Charles H. Evans, Jr.
}

$\mathrm{T}$ he new science of genomics endeavors to chart the genomes of individuals around the world, with the dual goals of understanding the role genetic factors play in human health and solving problems of disease and disability. From the perspective of indigenous peoples and developing countries, the promises and perils of genomic science appear against a backdrop of global health disparity and political vulnerability. These conditions pose a dilemma for many communities when attempting to decide about participating in genomic research or any other biomedical research. Genomic research offers the possibility of improved technologies for managing the acute and chronic diseases that plague their members. Yet, the history of biomedical research among people in indigenous and developing nations offers salient examples of unethical practice, misuse of data and failed promises. This dilemma creates risks for communities who decide either to participate or not to participate in genomic science research. Some argue that the history of poor scientific practice justifies refusal to join genomic research projects. Others argue that disease poses such great threats to the well-being of people in indigenous communities and developing nations that not participating in genomic research risks irrevocable harm. Thus, some communities particularly among indigenous peoples have declined to participate as subjects in genomic research. ${ }^{1}$ At the same time, they have begun developing new policies, procedures, and practices for engaging with the scientific community that offer opportunities to bridge the gap between genomic science and indigenous communities and/ or developing countries. From the perspective of the ethical, social, and legal issues facing genomic research, bridging the gap between indigenous people and genomic scientists offers lessons and models for conducting genomic research for the world community as a whole, particularly for vulnerable and high risk populations.

Bette Jacobs, Ph.D., is the Distinguished Professor and Co-Founder of the Georgetown University O'Neill Health Law Institute. Dr. Jacobs served for ten years as Dean of Georgetown School of Nursing and Health Studies. She is an enrolled member of Cherokee Nation and active leader in minority advancement organizations. Dr Jacobs holds a Ph.D. from the University of Texas, M.S. in public health nursing, and B.S. in nursing from California State University. Jason Roffenbender, M.S., is a Research Assistant for the O'Neill Institute at Georgetown University. Mr. Roffenbender earned an M.S. in physiology and biophysics from Georgetown University. Jeff Collmann, Ph.D., M.A., is the Center Director at the Disease Prevention and Health Outcomes and Associate Professor at the School of Nursing छ Health Studies at Georgetown University. Dr. Collmann holds a Ph.D. from Adelaide University (1980) in Australia and was a Post-doctoral Fellow at University of Tennessee from 1987-1990. He also holds a M.A.(Econ.) from the University of Manchester, U.K. (1975), and a B.A. from Lehigh University (1970) in Bethlehem, PA. Kate Cherry worked as a Research Assistant for the O'Neill Institute from 2007 to 2009. Ms. Cherry earned a B.A. in Public Policy from Duke University. LeManuel Bitsoí, Ed.D., M.Ed., is an enrolled member of the Navajo Nation, and former Post-doctoral Fellow in the O'Neill Institute. Dr. Bitsói earned a bachelor of science degree from the University of New Mexico (1995) and a master of education degree from Harvard University (1998). In 2007, he earned a doctorate from the University of Pennsylvania, where he conducted his doctoral dissertation research on the conditions that encourage and discourage American Indians from pursuing higher education. Kim Bassett worked as a Research Assistant for the O'Neill Institute from 2007 to 2009. Ms. Bassett earned a B.S. in International Health from Georgetown University. Charles H. Evans, Jr., M.D., Ph.D., is the former Chair of the Department of Human Science at the School of Nursing $\Xi$ Health Studies at Georgetown University Medical Center. He earned an M.D. and a Ph.D. in microbiology from the University of Virginia, and a B.S. in Biology from Union College. 


\section{Articulating the Dilemma}

The Personalized Healthcare Initiative, Department of Health and Human Services, and the O'Neill Institute for National and Global Health Law at Georgetown University jointly sponsored a colloquium entitled "Developing a Framework to Guide Genomic Data Sharing and Reciprocal Benefits to Developing Countries and Indigenous Peoples," held at Georgetown University on January 7-8, 2009, to promote and emulate collaborative discourse among the diverse constituencies contributing to the global discussion about genomic science. ${ }^{2}$ The colloquium included thought leaders from developing countries, indigenous peoples, genomic science, genomic medicine and global health, most of whom have participated in the international debate about genomics, indigenous peoples, and developing countries for many years.
(HGDP), the National Geographic Genographic Project, and others. ${ }^{3}$ From this perspective, the struggle of indigenous peoples worldwide to achieve recognition of their sovereignty and rights of self-determination informs the discussion about biomedical research, particularly when scientific investigators act in unethical ways. The Navajo offer a case in point.

\section{Case One: Moratorium on Genetic Research Studies within the Jurisdiction of the Navajo Nation}

In 2002, the Navajo Nation Council passed a moratorium banning all research activities involving genetics and genomics until amendment of the Navajo Nation Health Research Code. The purpose of the Navajo Nation Health Research Code is to "set forth the conditions under which investigators, physicians,

\section{From the perspective of the ethical, social, and legal issues facing genomic research, bridging the gap between indigenous people and genomic scientists offers lessons and models for conducting genomic research for the world community as a whole, particularly for vulnerable and high risk populations.}

The colloquium posed the question of how to assure that people in indigenous and developing nations realize the benefits from their participation in genomic research. Indigenous nations and developing countries share a history of underdevelopment and colonial exploitation that has often left their peoples politically and economically marginalized. People in these communities suffer disproportionately from both infectious diseases such as HIV/AIDS, malaria, and diarrhea and chronic illnesses such as diabetes and heart disease. Personalized medicine promises dramatic improvements in treatment for these illnesses through health care tailored to the genotype of individual patients. Yet, genomic science has just begun to collect the data necessary to support personalized medicine and requires some degree of participation by all the world's people to succeed in its objectives, including people in indigenous and developing nations.

Spokespersons from indigenous communities asserted, however, that genomic investigators should not presume that all communities would agree to participate in the research. Indeed, indigenous organizations such as the United Nations Working Group on Indigenous Peoples and many indigenous communities have already decided not to participate in genomic research citing negative experiences with earlier projects such as the Human Genome Diversity Project researchers and others may perform health and health related activities within the territorial jurisdiction of the Navajo Nation." 4 The Code aims to "ensure that all persons within the territorial jurisdiction of the Navajo Nation are free from unreasonable harmful, intrusive, ill-conceived or otherwise offensive research and

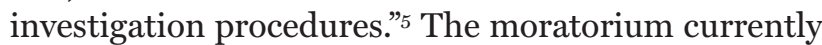
in place within the Navajo Nation does not indicate that the Navajo Nation government is entirely opposed to the possibility of participating in future genetic and genomic research studies to benefit its citizenry. The moratorium is not an obstacle, but an opportunity to partner with the Navajo Nation to establish a bilateral, mutually beneficial, and ethical relationship.

One opportunity identified in the moratorium grows out of the need to develop educational materials to inform the Navajo public before developing specific policy on genetic and genomic studies. ${ }^{6}$ Participating in collaboration with the Health and Social Services Committee of the Navajo Nation Council to work on these educational materials offers a possible avenue to re-establish a partnership between the Navajo Nation and biomedical science communities. Previous socio-medical partnerships with the Navajo outline important lessons learned prior to broaching future research. In his extensive analysis of a tuberculosis research study on the Navajo, David Jones notes the 
researchers "depended on the continued cooperation of the Navajo, [and] cultivated their relationship... with great care, celebrating the results of both treatment and research."7 The promotion of a long-term scientific relationship with the Navajo Nation must integrate enduring partnerships on respectful biomedical policy and education, as well as the basic science research itself.

Other participants in the colloquium, particularly spokespersons for developing countries, acknowledged the importance of sovereignty and colonial history but expressed great concern that people from their communities could easily miss benefitting from advances in personalized medicine as they had missed so many other technological "revolutions." Indeed, a "genomic gap" in both scientific research and healthcare already exists between Africa and the developed world that may be impossible to close. From this perspective, the global community faces a challenge not to let Africa fall farther behind in genomic science. Mexico offers an important case study because, as a developing country with many indigenous communities, it has faced the questions of scientific practice and health disparity in the design and implementation of its National Institute of Genomic Medicine (INMEGEN). ${ }^{8}$

\section{Bridging the Divide}

As the colloquium participants discussed these points and evaluated their implications for genomic science and health care, conversation began to focus on the fundamental importance of engaging indigenous and developing communities in the discussion about, and process of, genomic research. They drew attention to how, over the last two decades, many indigenous communities and scientists around the world have explored novel community-based research methods that could benefit both genomic science and indigenous communities, while also furthering global public health. ${ }^{9}$ These methods entail a model of research in which scientists and communities develop complex relationships composed of cultural exchange, mutual learning, and respect as well as data and sample collection. Implicit, too, is a new definition of "rigorous scientific research," one that includes both community development and scientific progress as legitimate objectives of genomic research. Participants in the Georgetown colloquium identified four processes that warrant special attention and further support: consulting with local communities; negotiating the complexities of consent; training members of local communities in science and health care; and training scientists to work with indigenous communities.
Standards for Consulting with Local Communities National and international organizations have developed standards for scientists to use in consulting with communities about the conduct of research. A matrix of guidelines for genomic research with indigenous populations presented in Figure I has been constructed based on the principles outlined by Richard Sharp and Morris Foster in An Analysis of Research Guidelines on the Collection and Use of Human Biological Materials from American Indian and Alaskan Native Communities. ${ }^{10}$ The categories included in the matrix are divided into five complementary principles: community consultation, sample collection and informed consent, use and storage of biological materials, prioritization of research uses, and post-research obligations. Guidelines are individually coded according to the complementary principles based on their inclusion or exclusion of 15 sub-principles. One axis of the matrix is the 15 sub-principles. The other axis of the matrix represents individual sets of guidelines listed by organization and year of publication. This work builds on the previous analysis by Sharp and Foster by applying the existing framework to more recent guidelines for ethical research with Indigenous populations. The selection criteria for guidelines is limited to those created by English-speaking countries or international bodies which explicitly address genomic research or generally address health research with Indigenous populations.

The matrix demonstrates the evolution of research guidelines over time. As late as the mid-1990s, guidelines rarely recommended community consultation. Today all of the recent guidelines published by staterun organizations explain the need for individual and community approval on issues such as secondary uses of data and withdrawal of samples. The matrix underscores the importance of explicitly consulting communities and individuals in efforts to conduct research with Indigenous populations. Guidelines have evolved from showing little emphasis on the enumeration of reciprocal benefits to the point where all guidelines require benefit sharing with contributing populations. An increasing number also takes a clear position on how to benefit contributing populations when research leads to commercial applications. The overall trend shown in the matrix is a movement towards guidelines that prescribe mutually beneficial and deeply collaborative research partnerships, many of which can be categorized within the framework of participatory research.

The CIHR Guidelines for Health Research Involving Aboriginal People (CIHR Guidelines) published by the Canadian Institutes of Health Research (CIHR) in 2007 present the most comprehensive contribution 
Figure I

Guidelines for Genomic Research with Indigenous Populations

\begin{tabular}{|c|c|c|c|c|c|c|c|c|c|c|c|c|}
\hline & 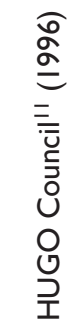 & 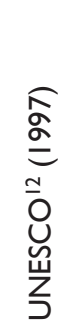 & 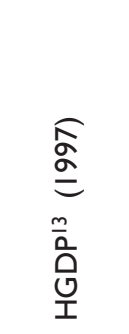 & 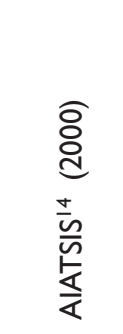 & 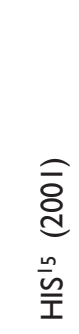 & 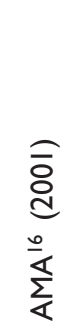 & 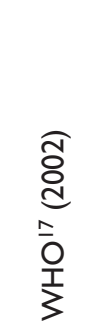 & 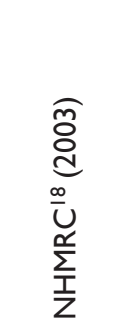 & 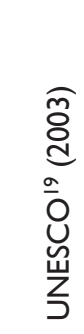 & 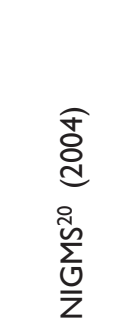 & 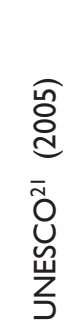 & 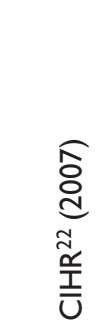 \\
\hline \multicolumn{13}{|l|}{$\begin{array}{l}\text { Community } \\
\text { Consultation }\end{array}$} \\
\hline In protocol development & & & $y$ & $y$ & & $y$ & $y$ & $y$ & & $y$ & $y$ & $y$ \\
\hline Before collection of samples & $y$ & & $y$ & $y$ & $y$ & $y$ & $y$ & $y$ & $y$ & $y$ & & $y$ \\
\hline $\begin{array}{l}\text { Embodies respect for } \\
\text { cultural differences }\end{array}$ & y & $y$ & y & $y$ & $y$ & & $y$ & $y$ & $y$ & $y$ & $y$ & $y$ \\
\hline $\begin{array}{l}\text { Formal community approval } \\
\text { required }\end{array}$ & & & $y$ & & $y$ & $y$ & $y$ & $y$ & & $y$ & & $y$ \\
\hline \multicolumn{13}{|l|}{$\begin{array}{l}\text { Sample Collection and } \\
\text { Informed Consent }\end{array}$} \\
\hline $\begin{array}{l}\text { Done in a culturally sensitive } \\
\text { manner }\end{array}$ & & $y$ & $y$ & $y$ & $y$ & & $y$ & $y$ & $y$ & $y$ & $y$ & $y$ \\
\hline $\begin{array}{l}\text { Discussion of a collective } \\
\text { harm (e.g. group discr) as part } \\
\text { of inform consent process }\end{array}$ & & $y$ & $y$ & $y$ & $y$ & & $y$ & $y$ & $y$ & $y$ & $y$ & $y$ \\
\hline \multicolumn{13}{|l|}{$\begin{array}{l}\text { Use and Storage of Biological } \\
\text { Materials }\end{array}$} \\
\hline $\begin{array}{l}\text { Potential uses defined prior } \\
\text { to sample collection }\end{array}$ & & & & $y$ & $y$ & $y$ & $y$ & $y$ & $y$ & $y$ & & $y$ \\
\hline $\begin{array}{l}\text { Provision for withdrawal of } \\
\text { samples (IW or CW) }\end{array}$ & & & IW,CW & IW,CW & & IW & $\mathrm{CW}$ & IW,CW & IW & IW,CW & IW & IW,CW \\
\hline $\begin{array}{l}\text { Discussion of secondary uses } \\
\text { with contributors (DI or DC) }\end{array}$ & & & $y$ & DI & & & DC & & DI & DI,DC & & DI,DC \\
\hline $\begin{array}{l}\text { Secondary uses require } \\
\text { community approval }\end{array}$ & & & & & $y$ & $y$ & $y$ & $y$ & $y$ & $y$ & & $y$ \\
\hline \multicolumn{13}{|l|}{ Prioritization of Research Uses } \\
\hline $\begin{array}{l}\text { Should benefit contributing } \\
\text { population }\end{array}$ & $y$ & y & $y$ & $y$ & $y$ & & $y$ & $y$ & $y$ & & $y$ & $y$ \\
\hline $\begin{array}{l}\text { Clear position on commer- } \\
\text { cial applications }\end{array}$ & $y$ & y & $y$ & $y$ & & & $y$ & & & & $y$ & $y$ \\
\hline \multicolumn{13}{|l|}{ Post-Research Obligations } \\
\hline $\begin{array}{l}\text { Ongoing research updates to } \\
\text { participating communities }\end{array}$ & $y$ & & $y$ & $y$ & & $y$ & $y$ & $y$ & $y$ & $y$ & $y$ & $y$ \\
\hline $\begin{array}{l}\text { Community review of study } \\
\text { findings before release }\end{array}$ & & & $y$ & $y$ & $y$ & & $y$ & $y$ & $y$ & $y$ & & $y$ \\
\hline $\begin{array}{l}\text { Need to develop local } \\
\text { capacities }\end{array}$ & & $y$ & $y$ & & & & & $y$ & & & $y$ & $y$ \\
\hline
\end{tabular}

Y signifies that the sub-principle is included in the indicated guideline(s). 
on this issue to date, and serve as a model for genomic research in other countries. The guidelines include three sections that provide the rationale for developing them, identify and explain the 15 principles upon which they rest, and offer examples of how to develop and codify research projects with indigenous peoples. Discussing all 15 of the coded sub-principles listed in the matrix, the guidelines capture the intended spirit of these principles in a comprehensive and concise manner and represent a checklist of what scientists should understand about conducting research with indigenous communities (see below). The CIHR Guidelines address many points of previous dispute between indigenous communities and biomedical scientists, such as re-consent for multiple uses of samples, acknowledgment of intellectual property rights, protection of indigenous rights in cultural and sacred knowledge as well as recognition of ownership and stewardship of data or biological samples. ${ }^{23}$ The spirit of the CIHR Guidelines, however, emerges from articles pertaining to the relationship that should develop between an indigenous community and researchers. Article 1 for example, enjoins researchers to "understand and respect Aboriginal world views, including responsibilities to the people that flow from being granted access to traditional or sacred knowledge. These should be incorporated into research agreements, to the extent possible." ${ }^{44}$ Beyond respect, however, indigenous communities also should be given the option of a participatory-research approach, have an opportunity to participate in the interpretation of the data and review the analysis to ensure "accuracy and cultural sensitivity of the interpretation," and, finally, decide how to acknowledge its participation in project reports and publications. ${ }^{25}$ Article 9 states, "Research should be of benefit to the community as well as to the researcher." ${ }^{26}$ Given the respective sovereignty of First Nation, Inuit, and Métis communities in Canada, these concerns should be addressed on a community-level and discussed prior to each research investigation.

The CIHR emulated the consultative process for which it advocates by engaging in extended consultations and deliberations with Canadian indigenous communities to develop the CIHR Guidelines. In March 2004 the CIHR established the Aboriginal Ethics Working Group (AEWG), an interdisciplinary, multicultural 12-member advisory team composed primarily of Indian, Inuit, and Métis people that eventually crafted the Guidelines. The Aboriginal Capacity and Developmental Research Environments (ACADRE), a university-based network of academic research communities and First Nation, Inuit, and Métis communities, worked with communities to translate traditional values and ethics into guidance for health researchers.
From these discussions, ACADRE produced a series of commissioned background papers that informed the deliberations of the AEWG. The AEWG met to write the Guidelines over the course of two years. Upon receiving a draft from the AEWG, the CIHR Ethics Office along with the National Council on Ethics in Human Research conducted workshops and consultations with Aboriginal communities, researchers, and members of research ethics boards to obtain feedback on the draft guidelines. CIHR and its partners electronically posted the document to enable widespread access and awareness, and to solicit comments prior to final revision. The draft guidelines were then edited by CIHR Ethics Office, in consultation with Health Canada and Justice Canada, to optimize internal consistency, and to ensure that the draft guidelines reflected CIHR's mandate. ${ }^{27}$ Through these workshops and consultations, the CIHR Guidelines emerged from a participatory, inclusive, and ongoing process. The consultations acknowledge the basic sovereignty and right of self-determination of indigenous peoples as expressed in United Nations General Assembly Resolution 61/295 within the Declaration on the Rights of Indigenous Peoples. ${ }^{28}$

Internationally, the Council for International Organizations of Medical Sciences (CIOMS), in collaboration with the World Health Organization, specifically outlines the needs for consultation with groups in the International Ethical Guidelines for Biomedical Research Involving Human Subjects. Researchers hoping to work with populations may present risks to those very same communities and therefore "the ethical review committee should ensure that the interests of all concerned are given due consideration; often it will be advisable to have individual consent supplemented by community consultation." ${ }^{29}$ United Nations Educational, Scientific and Cultural Organization's (UNESCO) Declaration on Universal Norms on Bioethics did not include guidelines encouraging community consultation when published in 2005, an omission that should be revisited and corrected in light of the work of the CIHR and WHO. ${ }^{30}$

\section{Negotiating Consent}

Article 4 of the CIHR Guidelines recognizes that community consent often precedes individual consent among indigenous peoples.

A researcher who proposes to carry out research that touches on traditional or sacred knowledge of an Aboriginal community, or on community members as Aboriginal people, should consult the community leaders to obtain their consent before approaching community members individually. 
Once community consent has been obtained, the researcher will still need the free, prior and informed consent of the individual participants (emphasis added). ${ }^{31}$

The phrase "on community members as Aboriginal people" entails many of the topics proposed for genetic investigation, including health issues such as the genetic basis for disease susceptibility or response to chemotherapeutic agents. Section 1.5 specifies the range of conditions under which this requirement might apply. For "Research directly and exclusively involving Aboriginal communities" and "Research involving Aboriginal people where they comprise a sizable proportion of the study or community and Aboriginal-specific conclusions are intended," researchers should seek community consent and/or consultation with community leaders. ${ }^{32}$ Good practice and the availability of relevant political bodies govern other research that, while engaging indigenous people in some way, may not entail consequences for specific indigenous communities. This flexible approach to community consultation and consent illustrates the importance of the motive that underlies CIHR's intent as stated in the opening "Purpose and Application" section of the Guidelines:

These Guidelines have been prepared by the Ethics Office of the Canadian Institutes of Health Research (CIHR), in conjunction with its Institute of Aboriginal Peoples' Health, to assist researchers and institutions in carrying out ethical and culturally competent research involving Aboriginal people. The intent is to promote health through research that is in keeping with Aboriginal values and traditions. The Guidelines will assist in developing research partnerships that will facilitate and encourage mutually beneficial and culturally competent research. The Guidelines will also promote ethics review that enables and facilitates rather than suppresses or obstructs research. ${ }^{33}$

The CIHR Guidelines explicitly highlight the benefits of obtaining community consent by noting, "Respect for community control includes ensuring the survival and protection of Aboriginal culture, heritage and knowledge." ${ }^{34}$ These benefits to indigenous communities, however, also pertain to the benefits of community consent for the overall research enterprise.

There is an increasing recognition that improvements in the health status of Aboriginal people require changes both at the community level and at the individual level. There is growing interest in working with communities to create healthful changes through academic/practice/community partnerships. There is also recognition that the knowledge, expertise and resources of the community are often key to successful research. While developing partnerships may require more time and effort initially, partnerships based on mutual trust and respect lead to better research and a more positive relationship with the communities and individuals affected by the research. Following the principles and articles embodied in these Guidelines will, over the long run, be beneficial for all parties involved. ${ }^{35}$

\section{Case Two: Nested Consent in National Institute of Genomic Medicine of Mexico} Mexico's National Institute of Genomic Medicine (INMEGEN), a large-scale genome variability project established in 2004, developed a comprehensive approach to consent in genomics research that demonstrates their broad relevance to meeting these challenges in developing countries as well as indigenous peoples. ${ }^{36}$ INMEGEN has included two phases to date. Phase 1 focused on genotyping the Mestizo population across the country including border states who provide many migrants to the USA. Phase 2 focused on genotyping indigenous people. In both phases INMEGEN provided extra funding and time to obtain "nested consent" at three levels: the individual, local community, and the state. ${ }^{37}$ INMEGEN worked with the Departments of Health in each Mexican state as well as local leaders from participating communities to enable state and local review of the research plans and procedures. INMEGEN implemented a broad, community-based consent process based on 12 questions and answers mounted on public posters, three weeks of public education in each state, and community meetings that enabled local media and community members to ask questions. Before sample collection, each participant had an individual session with an investigator to address any additional questions and sign the consent form with two witnesses of the local community. The consent form, based on the current federal laws in Mexico, included the eight guidelines from the International HapMap Project Ethical, Legal and Social Issues Program and reflected the 12-question format of the public campaign. INMEGEN trained local university students to collect samples at the university-based collection stations on behalf of the state governments. Phase 2 posed special challenges because indigenous people speak 65 separate languages, rarely speak Spanish, and often lack basic science education. INMEGEN adapted its consent process when working with indigenous communities, 
including explaining the project in local languages, translating the consent posters into local languages, and consulting with local chiefs to obtain community consent. INMEGEN did not agree to allow men to grant consent for women. People from two indigenous communities joined the university students as trained sample collectors. Some communities obtained health care services in exchange for their participation in the project. $^{38}$

\section{Case Three: Indigenous Human Research Review Boards}

Institutional Review Boards (IRBs) have emerged during the last decade throughout indigenous communities in the Americas and represent a point of origin for other innovations to support local participation in biomedical science and healthcare. ${ }^{39}$ The U.S. Indian Health Service (HIS) sponsors IRBs in all of its area offices to review research proposed for its own facilities, and offers the service to indigenous communities when requested. In 1996, the Navajo Nation assumed responsibilities for its local IRB from IHS that has drawn from the tradition of participatory action research to emphasize how research among the Navajo entails research in relationship with the Navajo as a sovereign nation. The Navajo Nation Human Research Review Board (NNHRRB) expanded its tribally based and tribally run review processes beyond the scope of traditional IRBs. The NNHRRB requires a 12-phase process of intense interaction between investigators and the community that includes participatory study design and prepublication manuscript review, as well as results dissemination and data acquisition. ${ }^{40} \mathrm{Bev}-$ erly Becenti-Pigman, Kalvin White, Bea Bowman, Nancy "Lynn" Palmanteer-Holder, and Bonny Duran, key leaders of the NNHRRB, describe the process as follows:

Phases I to III require researchers to verify community involvement and tribal participation in the research or approval process. In phase IV, research decisions are made. Phases V through VII provide input and support for researchers to ensure the accuracy and relevance of their work to the target population and to their respective professions. The dissemination phases, VII to XI, guarantee that the Navajo Nation will be adequately apprised of the research outcomes and findings. Finally, phase XII ensures that the $\mathrm{NN}$ will take possession of its own data. ${ }^{41}$

They also clarify the primary goal of the NNHRRB, stating "this is a rigorous process intended to ensure that culturally competent, ethical research is con- ducted. Such research is more likely than other studies to have a positive effect on both the Navajo Nation and the research scientists and institutions." 42 Through this process, the Navajo Nation assures respect for its sovereignty, ongoing collaboration in the research process, and a return on investment for the Navajo people. $^{43}$

\section{Training Members of Local Communities in Science and Health Care}

Training indigenous people in the science and practice of genomic medicine may enhance the effectiveness of community and individually based consultation and consent procedures. We focus here on three broad developments that warrant special attention and further support, including educating indigenous people in genomic science and its potential implications for their lives, increasing the number and impact of indigenous scientists and health care providers, and fostering community-based research in genomic investigations.

Over the last decade Bemis, Burhansstipanov, and Dignan developed a genomic curriculum entitled "Genetic Education for Native Americans (GENA ${ }^{\circledR}$ )" for Native American college and university students that was designed to promote understanding and discussion of the scientific, ethical, legal, social, and cultural implications of genomics for indigenous communities. ${ }^{44}$ Their curriculum includes a set of 24 learning objectives that intersperses instruction about Native American cultural and political concerns about genomics, topics in the basic science and clinical application of genomics, the organization of genomics research, methods for acceptably conducting research among Native American communities, and challenges for Native and Hispanic peoples in developing scientific careers. ${ }^{45}$ The entire curriculum requires about 16 hours of contact time but was crafted into 3-hour modules for presentation in unconventional workshop settings outside the classroom such as professional meetings. They have conducted quantitative and qualitative assessments documenting the effectiveness of their curriculum in improving understanding of genomics among Native American college students. ${ }^{46}$ The success of their approach among the targeted college audience justifies attempting to adapt it to other audiences within indigenous communities, including middle and high school children as well as adult community members such as tribal healers, tribal leaders, and the community at large.

In the U.S., Native Americans have made inroads in increasing the number of science, technology, engineering, and mathematics (STEM) graduates. As indicated in Figure 2, there has been a noticeable 
increase in the number of American Indian Ph.D. and M.D. graduates since 1992. The increase in their numbers at the doctoral level can be attributed to the focused efforts by various federal programs such as the Tribal Colleges and Universities Program (TCUP) of the National Science Foundation (NSF), Minority Action Plans (MAP) of the National Human Genome Research Institute-NIH, and the Indian Health Service Scholarship Program of the Department of Health and Human Services.

The NSF instituted the Tribal Colleges and Universities Program (TCUP) in 2001 to provide awards to enhance the quality of STEM instructional and outreach programs at TCUs. In addition, assistance is provided to TCUs to bridge the digital divide and prepare students for careers in STEM fields. ${ }^{48}$ MAP Programs are committed to increasing the number of underrepresented minority scientists in genome and ethical, legal, and social implications (ELSI) research. ${ }^{49}$ The Indian Health Service (IHS) Scholarship Program was established in 1977 to provide scholarships at three levels: preparatory, pre-graduate, and health professions. This program can explain the consistent number of American Indian physicians and health care graduates over the years.

National advocacy groups have also assisted in helping to produce an increased number of physicians, health care professionals, and scientists. Of the three most prominent advocacy groups for Native Americans, the Association of American Indian Physicians (AAIP) is the oldest, as it was founded in 1971 and offers educational programs, services, and activities to motivate American Indian and Alaskan Native students to pursue a career in health professions and/or biomedical research..$^{50}$ The next notable organization is SACNAS, which was established in 1973 to foster the success of Hispanic/Chicano and Native American scientists in attaining advanced degrees, careers, and positions of leadership. ${ }^{51}$ The third prominent organization is the American Indian Science and Engineering Society (AISES), which was founded in 1977 to increase number of American Indian and Alaskan Natives in engineering, science, and other related technology disciplines. ${ }^{52}$

Training and employing community members as researchers and health care workers builds human capital with the potential for yielding general

Figure 2

Native American M.D. and Ph.D. Graduate Trends

\begin{tabular}{|c|c|c|c|c|c|c|c|c|c|c|c|c|c|c|c|c|c|}
\hline & 1992 & 1993 & 1994 & 1995 & 1996 & 1997 & 1998 & 1999 & 2000 & 2001 & 2002 & 2003 & 2004 & 2005 & 2006 & 2007 & Total \\
\hline \multicolumn{18}{|c|}{$\begin{array}{l}\text { Ph.D., Bio- } \\
\text { logical \& } \\
\text { Biomedical } \\
\text { Sciences }\end{array}$} \\
\hline Total & 11 & 5 & 9 & 4 & 14 & 5 & 9 & 10 & 8 & 15 & 14 & 12 & 16 & 18 & 19 & 23 & 192 \\
\hline Male & 8 & 3 & 5 & 0 & 6 & 1 & 3 & 4 & 5 & 9 & 8 & 5 & 9 & 8 & 12 & 8 & 94 \\
\hline Female & 3 & 2 & 4 & 4 & 8 & 4 & 6 & 6 & 3 & 6 & 6 & 7 & 7 & 10 & 7 & 15 & 98 \\
\hline \multicolumn{18}{|c|}{$\begin{array}{l}\text { Ph.D., } \\
\text { Health } \\
\text { Professions } \\
\text { \& Related } \\
\text { Clinical } \\
\text { Sciences }\end{array}$} \\
\hline Total & 3 & 4 & 7 & 9 & 2 & 5 & 6 & 9 & 8 & 10 & 8 & 12 & 19 & 26 & 18 & 26 & 172 \\
\hline Male & 0 & 1 & 1 & 2 & 1 & 1 & 0 & 1 & 1 & 3 & 3 & 8 & 5 & 10 & 8 & 6 & 51 \\
\hline Female & 3 & 3 & 6 & 7 & 1 & 4 & 6 & 8 & 7 & 7 & 5 & 4 & 14 & 16 & 10 & 20 & 121 \\
\hline \multicolumn{18}{|c|}{$\begin{array}{l}\text { M.D., Phy- } \\
\text { sicians, etc. }\end{array}$} \\
\hline Total & 67 & 73 & 68 & 65 & 93 & 111 & 119 & 125 & 124 & 88 & 123 & 109 & 111 & 96 & 143 & 123 & 1,638 \\
\hline Male & 34 & 34 & 41 & 28 & 54 & 70 & 60 & 68 & 64 & 45 & 63 & 56 & 58 & 52 & 70 & 68 & 865 \\
\hline Female & 33 & 39 & 27 & 37 & 39 & 41 & 59 & 57 & 60 & 43 & 60 & 53 & 53 & 44 & 73 & 55 & 773 \\
\hline
\end{tabular}

SOURCE: U.S. Department of Education, National Center for Education Statistics 47 
improvements in the local standard of living. Community investigators also facilitate what during the colloquium Ian Wronski called "morally valid" consent; that is, consent based on cross-cultural translation of science and local traditions. ${ }^{53}$ Community members with understanding of both genomics and local culture potentially function as "champions" for science as well as protectors of their community. ${ }^{54}$ Community investigators may also help assure that research focuses on topics relevant to local communities, prepare communities for scientific advances, and facilitate the adaptation of local culture and customs to changing circumstances. ${ }^{55}$
The concept of "community" may vary in scope depending on the circumstance. The KSDPP project clearly refers to a group of people living together in a single location. Yet, "indigenous community" may also refer to national or international entities such as the United Nations Permanent Forum on Indigenous Peoples. From a national perspective, over the last decade the National Health and Medical Research Council (NHMRC) of Australia has developed a fourprong approach to investment in indigenous health research as a means of contributing to improving the poor health status of indigenous Australians that sets indigenous health goals and includes indigenous

\section{The novel processes of consultation, consent, and local participation outlined above pose challenges for genomic scientists wanting to conduct research among indigenous peoples. Thus, as the "Genetic Education for Native Americans" program seeks better to inform indigenous college students and other indigenous community members about genomics, a comparable program should be developed better to inform genomic scientists about working with indigenous communities.}

The presence of informed community members and indigenous scientists creates an opportunity for effective community-based research on topics of local choosing and marks a standard for research in indigenous communities. ${ }^{56}$ The Kahnawake Schools Diabetes Prevention Project (KSDPP) in Quebec, Canada, a community-university participatory research and intervention project to prevent Type II diabetes among adolescent Mohawks illustrates what can be achieved in establishing solid community-investigator partnerships. As Ann Macauley and colleagues report, the KSDDP "aims to mobilize the community for the promotion of healthy lifestyles, with the long-term goal of preventing diabetes and so ensuring good health for present and future generations of Kanien'kehá:ka (The Seven Generations)." ${ }_{57}$ The KSDPP put in place a comprehensive Community Advisory Board that emulates traditional tribal decision-making processes in collaboration with university investigators. ${ }^{58}$ The results of studies documenting the local prevalence of diabetes and complications associated with diabetes were returned to the community. The project also developed a Code of Research Ethics to ensure that community members are equal partners with the researchers and to build "local capacity by making the project a learning opportunity for all." 59 leaders at the national level. With indigenous health research goals and intentions embedded in the strategic plan, the NHMRC has developed a strong work plan to:

- Provide guidance to the broader research community to focus activity on national priorities, through the development and dissemination of the Strategic Framework for Improving Aboriginal and Torres Strait Islander Health through Research and Final Report of Community Consultations on the NHMRC Road Map ${ }^{60}$;

- Develop high level ethical and research processes to govern the conduct of research which involves and/or impacts on indigenous people, including ethical guidelines that are a part of the national peer-review assessment processes for research grant applications;

- Improve participation of Aboriginal and Torres Strait Islander people in the policy and decision making processes of the NHMRC as the peak national health research body; this entails representation on committees (policy and peerreview), and as members of staff; and

- Build capacity of Aboriginal and Torres Strait Islander people to undertake research relevant to their communities, with significant emphasis 
placed on indigenous capacity building through the above-mentioned criteria.

\section{Training Scientists to Work with \\ Indigenous Communities}

The novel processes of consultation, consent, and local participation outlined above pose challenges for genomic scientists wanting to conduct research among indigenous peoples. Thus, as the "Genetic Education for Native Americans" program seeks better to inform indigenous college students and other indigenous community members about genomics, a comparable program should be developed better to inform genomic scientists about working with indigenous communities. The time is ripe for such a program because the United States National Institutes of Health has called for new and more rigorous training in responsible research as part of its revised review criteria. ${ }^{61}$ Assuring effective interaction among genomic scientists and indigenous communities requires multifaceted training, however, that imparts requisite knowledge and useful skills as well as social support for scientists and indigenous communities as they work together. ${ }^{62}$

The international discussion about research with indigenous communities suggests five general topics that should structure any training program for scientists, including:

- Assuring benefit and accountability to the indigenous community;

- Protecting the sensitivity and local control of information;

- Acknowledging the indigenous community's interest in data and biological samples; and

- Engaging the indigenous community as coinvestigator with researchers, and

- Understanding research as an ongoing, crosscultural relationship with self-determining indigenous communities.

Some issues such as the need to address the anonymity, privacy, and confidentiality of individuals and communities participating in research are familiar to most health researchers from regulations governing research with the general community, such as the privacy and security requirements encoded in the Health Insurance Portability and Accountability Act of $1996 .{ }^{63}$ Others refer almost exclusively to the circumstances of indigenous communities such as the suggestion that researchers have an obligation to learn about, and apply, Aboriginal cultural protocols relevant to the Aboriginal community involved in the research. Still others entail new obligations not characteristic of current research approaches with any community, such as the suggestion that research projects should support education and training of Aboriginal people in research methods and ethics.

When learning about these topics, genomic scientists will need information about both the general issue as it affects any indigenous community and information relevant to the specific community with which they propose to work. For example, Article 11.1 of the CIHR Guidelines invokes an obligation to learn about and apply Aboriginal protocols relevant to the Aboriginal community involved in the research. ${ }^{64}$ Instruction in the controversy about indigenous participation in the Human Genome Diversity Project would help scientists better understand why they need to incorporate "Aboriginal protocols" into a research process. Tribal experts will have to supplement this general introductory knowledge, however, with details of their own local ways of proceeding that scientists will need to incorporate into the research process. The Kahnawake Schools Diabetes Prevention Project represents a successful example from which to draw encouragement and lessons.

As a major contribution to aid scientists and communities in developing skills necessary for effective research relationships, the CIHR Guidelines include an adaptable, three-step graphical model for developing a health research project among Canadian indigenous peoples. ${ }^{65}$ This model portrays research as a developmental process that both depends on, and fosters productive social relationships among scientists and communities of study. Section 3.2, "Protocol and Research Process," outlines what must be done to plan, fund, explain, seek consent, and gain approval for a project as well as collect, interpret, and publish data. Taken as a pair, Section 3.1. and 3.2 of the CIHR Guidelines suggest that necessary skills for research with indigenous peoples include both the social skills of community-relationship building and the technical skills of scientific project execution.

The developmental model of research outlined here presumes ongoing support of scientists and community members in their collaboration. The literature reports community-based innovations that offer such support, particularly examples of indigenous human subject research boards that oversee projects from conception to completion. The Navajo Nation Human Research Review Board holds biannual meetings for all scientists conducting research under its jurisdiction to address important issues of the day and reaffirm the relationships among scientists and the community. From the institutional perspective, however, fuller support of the relationship between scientists and indigenous communities would occur if effective relationships also emerged between the human 
research review boards of the participating organizations. Current approval processes do not necessarily entail coordination among the human research review boards of participating organizations and, certainly, no mutual obligations jointly to support the university-based and community-based investigators in their work. Yet, this should occur in some way because both the university-based and the community-based investigators represent their broader institutional as well as their individual interests in the research process. Such procedures would recognize the sociological point that scientists as well as indigenous people are members of communities with vital interests in the execution and outcome of the research project.

\section{Conclusion}

The recently settled case of secondary use of DNA samples from the Havasupai tribe by researchers from Arizona State University illustrates the fundamental importance of these issues. ${ }^{66}$ An opportunity now exists to draw important lessons from this case: had the ASU researchers and Havasupai practiced the processes of consultation, consent, and collaboration here outlined, the dispute may never have started. Indigenous people and scientists in Canada, the United States, Mexico, Australia, and elsewhere have demonstrated innovative approaches to participatory research design, review, and management that offer paths across the genomic divide. These new approaches foster crosscultural interactions in which both parties understand that they see one another through their own social and cultural perspectives, bringing those sometimes-diverging perspectives to the negotiating table. These approaches need to become widely understood and accepted, if not standardized, in the genomic research community. This will require changes not only in how genomic research projects are organized and conducted, but in the expectations for results. ${ }^{67}$ Scientists will overcome few challenges of genomics without collaborating with indigenous people in genomic research. For many indigenous communities, the benefits of genomic science seem too remote and long term to warrant accepting the risks of research without locally acceptable safeguards. Innovative translational research is needed to develop practical, mutually acceptable methods for crossing the divide between genomic researchers and indigenous communities. This may mean the difference between success and failure in genomic science, and in improving health for all peoples.

\section{References}

1. O'Neill Institute for National and Global Health Law on the Internet, Developing a Framework to Guide Genomic Data Sharing and Reciprocal Benefits to Developing Countries and Indigenous Peoples: A Colloquium, available at <http://aspe.hhs.gov/sp/reports/2009/genshare/report.shtml> (last visited August 5, 2010); C. MacIntosh, "Indigenous SelfDetermination and Research on Human Genetic Material: A Consideration of the Relevance of Debates on Patents and Informed Consent, and the Political Demands on Researchers," Health Law Journal 13, no. 13 (2005): 213-251.

2. Id. (O'Neill Institute).

3. J. Reardon, Race to the Finish: Identity and Governance in an Age of Genomics (Princeton : Princeton University Press, 2005); K. Tallbear, "Narratives of Race and Indigeneity in the Genographic Project," Journal of Law, Medicine E Ethics 35, no. 3 (2007): 412-424; A. Harmon, "DNA Gatherers Hit a Snag: The Tribes Don't Trust Them," New York Times, December 10, 2006, at A1.

4. Health and Social Services Committee, Navajo Nation Council, HSSCAP-20-02 (2002).

5. Id.

6. Id.

7. D. S. Jones, "The Health Care Experiments at Many Farms: The Navajo, Tuberculosis, and the Limits of Modern Medicine, 1952-1962," Bulletin of the History of Medicine 76, No. 4 (2002): 749-790.

8. B. Seguin et al., "Genomics, Public Health and Developing Countries: The Case of the Mexican National Institute of Genomic Medicine," Nature Reviews Genetics (October 2008): S5-S9. This paper reflects the joint effort of colloquium participants, staff of the O'Neill Institute, and staff of the Personalized Healthcare Initiative. Researchers from the O'Neill Institute and the Personalized Healthcare Initiative began investigating the open literature to better understand the context and content of the colloquium before the colloquium. Without in any way attempting to preempt discussion during the colloquium, we sought to identify common concerns about genomic science, clarify lessons learned from past experience and briefly compare formal codes, guidelines and protocols that have been developed to regulate research and healthcare related to genomic science among indigenous people and developing countries. The colloquium developed through short presentations from each participant on the general topics of "Hearing the Indigenous Perspective," "Hearing the Perspectives of Developing Countries," and "Implications for Healthcare and Genomic Science" with open discussion following the talks on each topic. After hearing and initially discussing the ideas of all participants, the colloquium continued by identifying and suggesting approaches to key issues that had emerged from its work. This discussion formulated the four key topics discussed in the body of this paper. The O'Neill Institute prepared and submitted a colloquium report entitled "Thematic Analysis of Colloquium" in partial fulfillment of its obligation to the Personalized Healthcare Initiative, Department of Health and Human Services who helped support the colloquium. The O'Neill Institute sent drafts of the colloquium report to all participants for review, comment and revision. The final report reflected the perspectives of all participants who have received a copy for their own records. We have supplemented the background research and colloquium discussion with additional material drawn from the literature and available databases about relevant topics in writing this paper.

9. Twelve international thought leaders gathered at Georgetown University to discuss these issues in January 2009 in a colloquium jointly sponsored by the Personalized Health Care Initiative, Department of Health and Human Services and the O'Neill Institute of National and Global Health Law Georgetown University. Participants included Doris Cook, Theresa Cullen, Jacinta Elston, Tonya Gonnella Frichner, James M. 
Galloway, Bette Keltner Jacobs, Gerardo Jimenez-Sanchez, Ted Mala, Clifton A. Poodry, Charles Rotimi, Rodrigue Takoudjou, and Ian Wronski. Representatives from the O’Neill Institute included Kimberly Bassett, Katherine Cherry, Jeff Collmann, Julie DeLoia, Charles H. Evans, Jr., Kevin Fitzgerald, S.J., and Jason Roffenbender. Gregory J. Downing, Jennifer Weisman, and Jessica Nadler represented the Personalized Health Care Initiative.

10. R. R. Sharp and M. W. Foster, "An Analysis of Research Guidelines on the Collection and Use of Human Biological Materials from American Indian and Alaskan Native Communities," Jurimetrics 42 (2002): 165-186.

11. Human Genome Organization, Ethical, Legal, and Social Issues Committee Statement on the Principled Conduct of Genetic Research, HUGO Ethical, Legal, and Social Issues Committee Report to HUGO Council, 1996.

12. United Nations Educational, Scientific and Cultural Organization, Universal Declaration on the Human Genome and Human Rights, November 11, 1997.

13. Human Genome Diversity Project, Model Ethical Protocol for Collecting DNA Samples, 1997.

14. Australian Institute of Aboriginal and Torres Strait Islander Studies, Guidelines for Ethical Research in Indigenous Studies, May 2009.

15. Indian Health Service, IHS Guidelines for Implementing and Complying With HIS Policy on Specimens, March 31, 2001.

16. American Medical Association, Code of Medical Ethics: E-2.079 Safeguards in the Use of DNA Databanks in Genomic Research, 2001.

17. World Health Organization, Indigenous Peoples and Participatory Health Research, 2002.

18. National Health and Medical Research Council, Values and Ethics: Guidelines for Ethical Conduct in Aboriginal and Torres Strait Islander Research, 2003.

19. United Nations Educational, Scientific and Cultural Organizations, International Declaration on Human Genetic Data, Adopted October 16, 2003.

20. National Institute of General Medical Sciences, Policy for the Responsible Collection, Storage and Research Use of Samples From Named Populations for the NIGMS Human Genetic Cell Repository, August 25, 2004.

21. United Nations Educational Scientific and Cultural Organization, Preliminary Draft Declaration on Universal Norms on Bioethics, February 9, 2005.

22. Canadian Institutes of Health Research, CIHR Guidelines for Health Research Involving Aboriginal People, Ottawa, Canada, May 2007, available at <http://www.cihr-irsc.gc.ca/e/29134. html $>$ (last visited August 4, 2010).

23. $I d$.

24. Id., at 36 .

25. Id., at 37 .

26. See CIHR, Id., at 36 .

27. See CIHR, supra note 22, at 3.

28. United Nations, Declaration on the Rights of Indigenous Peoples 61/295, 2007.

29. Council for International Organizations of Medical Sciences, International Ethical Guidelines for Biomedical Research Involving Human Subjects, 2002.

30. See United Nations, supra note 28.

31. See CIHR, supra note 22, at 20.

32. Id., at 13 .

33. $I d$., at 2 .

34. Id., at 19

35. Id., at 12

36. See Seguin et al., supra note 8 .

37. Id.; C. Lara-Alvarez et al., "Ethical, Legal and Social Aspects of the Mexican Genomic Variability Project," Abstract Human Genome Organization Workshop (2008); R. Sharp and M. Foster, "Involving Study Populations in the Review of Genetic Research," Journal of Law, Medicine Eं Ethics 28, no. 1 (2000): 41-51.

38. Id. (Lara-Alvarez et al.); see Seguin et al., supra note 8.
39. C. Smith-Morris, "Autonomous Individuals or Self-Determined Communities? The Changing Ethics of Research among Native Americans," Human Organization 66, no. 3 (2007): 327-336.

40. D. Brugge and M. Missaghian, "Protecting the Navajo People through Tribal Regulation of Research," Science and Engineering Ethics 12, no. 3 (2006): 491-507.

41. B. Becenti-Pigman et al., Research Policies, Processes and Protocol, Appendix H, Navajo Nation Human Research Reviere Board (2008), available at <http://depts.washington.edu/ deptgh/docs/Appendix_H2DNavajo_Nation_HRRB_Protocol-2.pdf> (last visited August 4, 2010)

42. $I d$.

43. These approaches to "community consent" differ from the concept of "group consent" initially proposed by the Model Ethical Protocol (MEP) of the Human Genome Diversity project. The key difference lies in the fundamental justification for the two consents and the entities to which they apply. Community consent derives from sociological criteria of community sovereignty, self-governance, and self-determination. The MEP concept of group consent derives from biological criteria that do not necessarily overlap with extant social groups and, as Reardon notes, poses fundamental questions about who defines the "group," by what criteria, and for what research purpose (see Reardon, supra note 3). In practice, the researchers defined the "groups" using criteria defined by the research protocol. In contrast, the procedures of community consent apply when indigenous research subjects live under the jurisdiction of some kind of self-governing indigenous community that defines the community using self-determined criteria of citizenship. Membership in the community rather than sampling criteria in a research protocol define the scope of consent procedures. The CIHR Guidelines give a range of circumstances to which the procedures of community consent might apply in varying ways. The Guidelines acknowledge the possibility that the procedures of community consent may not apply to research conducted with individuals living outside the jurisdiction of a self-governing indigenous community (see CIHR, supra note 22).

44. L. Burhansstipanov et al., "Native American Cancer Education: Genetics and Cultural Issues," Journal of Cancer Education 16, no. 3 (2001): 142-145; M. Dignan et al., "Successful Implementation of Genetic Education for Native Americans Workshops at National Conferences," Genetics 169 (February 2005): 517- 521 .

45. Id. (Burhansstipanov et al.)

46. See Dignan et al., supra note 44.

47. U.S. Department of Education, National Center for Education Statistics, NCES Number 92097 (1992); NCES Number 93292 (1993); NCES Number 94115 (1995); NCES Number 96133 (1996); NCES Number 98015 (1997); NCES Number 1999036 (1998); NCES Number 200031 (1999); NCES Number 2001034 (2000); NCES Number 2002130 (2001); NCES Number 2003061 (2002); NCES Number 2005017 (2003); NCES Number 2006005 (2004); NCES Number 2006030 (2005); NCES Number 2007017 (2006); NCES Number 2008023 (2007); NCES Number 2009021 (2008), available at <http://nces.ed.gov/programs/digest/> (last visited August $4,2010)$.

48. National Science Foundation, "Tribal Colleges and Universities Program," available at <http://www.nsf.gov/funding/ pgm summ.jsp?pims id=5483> (last visited August 4, 2010).

49. National Human Genome Research Institute, "Minority Action Plan," available at <http://www.genome.gov/14514228> (last visited August 4, 2010).

50. Association of American Indian Physicians, "About AAIP," available at <http://www.aaip.org/?page=Overview> (last visited August 4, 2010).

51. Society for Advancing Hispanics/Chicanos \& Native Americans in Science, "Historical Overview," available at <http:// www.sacnas.org/historicalOverview.cfm > (last visited August $4,2010)$. 
52. American Indian Science and Engineering Society, "About Us," available at <http://www.aises.org/AboutUs> (last visited August 4, 2010).

53. See Smith-Morris, supra note 39.

54. $I d$.

55. Communities not interested in training as scientists should, however, also be able to benefit from genomic research. The Amish provide a strong example of a community fully interested in participating in genomic research, but not necessarily interested in training as scientists. K. Ruder, "Genomics in Amish Country," Genomic News Network, July 23, 2004.

56. M. Cargo et al., "Community Governance of the Kahnawake Schools Diabetes Prevention Project, Kahnawake Territory, Mohawk Nation, Canada," Health Promotion International 18, no. 3 (2003): 177-187.

57. A. Macauley et al., "Community Empowerment for the Primary Prevention of Type 2 Diabetes: Kanien'kehá:ka (Mohawk) Ways for the Kahnawake School Diabetes Prevention Project," in M. Leal Ferreira and G. Chesley Lang, eds., Indigenous Peoples and Diabetes: Community Empowerment and Wellness, (Durham: North Carolina Press, 2006).

58. Id.; J. Grignon, K. A. Wong, and S. D. Seifer, Ensuring Community-Level Research Protections, Proceedings of the 2007 Educational Conference Call Series on Institutional Review Boards and Ethical Issues in Research (Seattle, WA: Community-Campus Partnerships for Health, 2008).

59. See Macauley et al., supra note 57.
60. National Health and Medical Research Council, The NHMRC Road Map: A Strategic Framework for Improving Aboriginal and Torres Strait Islander Health through Research and Final Report of Community Consultations on the NHMRC Road Map, available at <http://www.nhmrc.gov.au/publications/ synopses/r28syn.htm> (last visited August 4, 2010).

61. National Institutes of Health, Update on the Requirement for Instruction in the Responsible Conduct of Research, available at <http://grants.nih.gov/grants/guide/notice-files/NOTOD-10-019.html $>$ (last visited August 4, 2010).

62. R. White, Putting Risk in Perspective: Black Teenage Lives in the Era of AIDS (Maryland: Rowman \& Littlefield Publishers, Inc., 1999).

63. Health Insurance Portability and Accountability Act of 1996, available at <http://www.cms.hhs.gov/hipaageninfo/downloads/hipaalaw.pdf > (last visited August 4, 2010).

64. See CIHR, supra note 22, at 5.

65. Id., at 28 .

66. A. Harmon, "Informed Consent' and the Ethics of DNA Research," New York Times, April 23, 2010; A. Harmon, "Indian Tribe Wins Fight to Limit Research of Its DNA," Nerw York Times, April 21, 2010.

67. National Health and Medical Research Council, Values and Ethics: Guidelines for Ethical Conduct in Aboriginal and Torres Strait Islander Health Research, Australian Health Ethics Committee, 2003. 